\title{
A Stackelberg Game Model of Trade in Renewable Resources with Competitive Sellers ${ }^{1}$
}

by

\author{
Amitrajeet A. Batabyal $^{2}$
}

and

\section{Hamid Beladi ${ }^{3}$}

We thank an anonymous referee and E. Kwan Choi for their comments on a previous version of this paper. Batabyal acknowledges financial support from the Gosnell endowment at RIT. The usual disclaimer applies.

2

Department of Economics, Rochester Institute of Technology, 92 Lomb Memorial Drive, Rochester, NY 14623-5604, USA. Internet aabgsh@rit.edu

3

Department of Economics and Finance, University of Dayton, 300 College Park, Dayton, OH 45469-2251, USA. Internet beladi@udayton.edu 


\title{
A Stackelberg Game Model of Trade in Renewable Resources with Competitive Sellers
}

\begin{abstract}
We model international trade in renewable resources between a single buyer and competitive sellers as a Stackelberg differential game. The buyer uses unit and ad valorem tariffs to indirectly encourage conservation of the renewable resource under study. First, we show that the efficacy of these trade policy instruments in promoting conservation depends fundamentally on whether harvesting costs are stock dependent or independent. When harvesting costs are stock independent, the optimal open loop tariffs are dynamically consistent. In contrast, when harvesting costs are stock dependent, the optimal open loop tariffs are dynamically inconsistent. Second, we point out that whether the terminal value of the resource stock is higher with the stock independent or the stock dependent cost function cannot be resolved unambiguously. Third, we show that it does not make sense for the buyer to use both tariffs simultaneously. Finally, we discuss the implications of these and other findings for renewable resource conservation in general
\end{abstract}

Keywords: Conservation, Renewable Resource, Stackelberg Game, Tariff, Trade

JEL Classification: F12, F18, Q20 


\section{A Stackelberg Game Model of Trade in Renewable Resources with Competitive Sellers}

\section{Introduction}

Renewable resources such as fish, timber (from forests), ivory (from elephants) and horns (from rhinoceroses) have been traded between countries for quite some time. However, considerable concern has recently been expressed about the declining stock levels of most salient renewable resources. ${ }^{4}$ As such, researchers and conservationists have now begun to systematically analyze questions about (i) the desirability of international trade in renewable resources and (ii) the efficacy of trade policies in promoting the conservation of these renewable resources.

This paper is concerned with the second of these two questions. However, before we move to the specifics of the paper itself, let us first summarize the relevant literature on international trade in renewable resources. Barbier and Schulz (1997) conclude that "ambiguous stock effects make trade interventions a poor policy instrument for securing biodiversity conservation” (Barbier and Schulz, 1997, pp. 160-161). Schulz (1997) shows that the effects of trade sanctions depend not only on the bioeconomic interactions between the species but also on the management system in the targeted country. Consequently, the threat of trade sanctions will not necessarily result in lower harvesting and higher stocks of marine mammals.

In an interesting two-country, two-good model of trade in renewable resources, Brander and Taylor (1998) demonstrate that not only is the basic "gains from trade" idea undermined by the presence

4

For more on this see, Clark (1973), Jablonski (1991), and Pimm et al. (1995). 
of open access renewable resources but that tariffs imposed by a resource importing country always benefit the resource exporter. Examining a two country model of the effects of unilateral fishery management, Emami and Johnston (2000) argue that the trade induced losses that arise from not managing this fishery can be mitigated by levying import tariffs on the resource good. Maestad (2001) shows that depending on the manner in which trade restrictions affect the log prices of alternate tree qualities, trade restrictions may decrease or increase timber logging.

The question of the efficacy of trade policies in promoting the conservation of renewable resources has probably been discussed most extensively in the context of the ivory trade between developing countries in Africa and East Asian and western nations. In an early contribution, Barbier et al. (1990) argued against a ban on trade in ivory and proposed an alternate strategy. This strategy would permit limited trade in ivory and the objective of this strategy would be to create sufficient incentives for the sustainable management of African elephant populations. In the aftermath of the CITES ban on ivory trade, Bulte and van Kooten (1999) examined the desirability of permitting some ivory trade. Bulte and van Kooten (1999) caution against lifting the trade ban. Specifically, they point out that permitting some trade in ivory would encourage illegal poaching and that this could drive the African elephant to extinction. In a more recent contribution, Heltberg (2001) uses a numerical model to conclude that the ivory trade ban is likely to reduce poaching.

Although these studies have certainly advanced our understanding of many aspects of international trade in renewable resources, none of these studies have analyzed the connections between renewable resource harvesting costs and trade policy. In particular, how does the stock dependence/independence of harvesting costs affect the efficacy of trade policy? Although researchers thus far have not studied this 
question, as we shall see, the form of the harvesting cost function has profound implications for the efficacy of trade policy in promoting the conservation of renewable resources.

The rest of this paper is organized as follows: Section 2 provides a detailed description of the Stackelberg differential game model of international trade in a renewable resource between a single buyer and competitive sellers. Section 3 analyzes the effects of trade policy when the renewable resource harvesting cost function is stock independent. Section 4 does the same for the case in which the harvesting cost function is stock dependent. Finally, section 5 concludes and offers suggestions for future research on international trade in renewable resources.

\section{The Stackelberg Differential Game}

Our model is adapted from Karp (1984) and Batabyal (1996). There is a single buyer (the leader) of the renewable resource and this buyer faces competitive sellers (the followers). If the renewable resource is ivory, then the reader should think of our model as a description of the interaction between competitive ivory sellers in the developing countries of Africa and a buyer with market power such as Japan. ${ }^{5}$ Denote the stock of the renewable resource at time $t$ by $x(t) .{ }^{6}$ The buyer's utility from consuming the resource at harvest level $h(t)$ is given by the concave and differentiable utility function $u(h)$. The domestic market in the buyer's country is competitive so that $u^{\prime}(h)=p(h)$, the price that consumers in the importing nation pay for this resource. The government of the importing nation has access to two trade policy instruments: a unit tariff denoted by $n(t)$ and an ad valorem tariff denoted by $a(t)$ where $v=1 /(1+a)$. When the

5

For a splendid account of the African elephant in general and the ivory trade in particular, see Meredith (2001).

6

In the rest of this paper we shall frequently suppress the time dependence of the various variables. However, the reader should note that all the variables that we work with depend on time. 
government in the importing nation uses the unit tariff $n(t)$, the price received by the competitive sellers (exporters) is $p(h)-n(t)$. Similarly, when this government uses the ad valorem tariff $a(t)$, the price received by the exporters is $v(t) p(h)$.

The buyer's payoff in the finite horizon (from time $t=0$ to $t=T$ ) games to be analyzed in this paper is the discounted stream of the difference between the utility of consuming the resource at level $h(t)$ and the payment to the competitive sellers. Consequently, if we denote the interest rate by $r$, then the buyer's payoff is

$$
J_{b}=\int_{0}^{T} e^{-r t}[u(h)-\{p(h)-n\} h] d t,
$$

when he uses a unit tariff. Similarly, when he uses the ad valorem tariff, his payoff is

$$
J_{b}=\int_{0}^{T} e^{-r t}[u(h)-v p(h) h] d t .
$$

The competitive seller maximizes profit and the seller gets no utility from consuming the resource under study. A major objective of this paper is to demonstrate the dependence of optimal trade policy on the cost of harvesting the renewable resource $x$. To this end, we analyze two kinds of harvesting cost functions. The first kind of cost function—analyzed in section 3 -is stock independent and it depends only on the harvest level. Denote this thrice differentiable cost function by $c(h)$, where $h$ is harvest, $c^{\prime}(h) \geq 0$ and $c^{\prime \prime}(h) \geq 0$. The second kind of cost function—analyzed in section 4 - depends on the stock and on the harvest level. Let us denote this cost function by $c(x) h$, where $c^{\prime}(x) \leq 0$ and $c^{\prime \prime}(x) \geq 0$. Ceteris paribus, 
the stock independent cost function is more relevant when the amount harvested is small relative to the total size of the resource stock. In contrast, the stock dependent cost function is more relevant when the total size of the stock is small to begin with and/or when the amount harvested is a significant fraction of the total stock size. When the buyer uses a unit tariff, the seller's payoff is

$$
J_{s}=\int_{0}^{T} e^{-r t}[p(h) h-n h-C(\cdot)] d t
$$

and when this buyer uses the ad valorem tariff, the seller's payoff is

$$
J_{s}=\int_{0}^{T} e^{-r t}[v p(h) h-C(\cdot)] d t,
$$

where $C(\cdot)$ in equations (3) and (4) is $c(h)$ and $c(x) h$, respectively.

The buyer controls the tariffs $n(t)$ and $v(t)$, and the seller controls the harvest $h(t)$. As the leader, the buyer announces a tariff trajectory at the beginning of the game and the seller takes this trajectory as given. The buyer and the seller are constrained by the differential equation describing the dynamics of the resource stock. That equation is

$$
d x(t) / d t=\ddot{x}=b x-h(t)
$$

where $0<b<r<\infty$ and $x(0)=x_{0}>0$ is given. In other words, the temporal net change in the resource stock is the difference between the natural growth $b x$ and the harvest $h(t){ }^{7}$

\footnotetext{
Replacing the linear natural growth function with a general growth function $f(x)$ does not alter the main points that we make in this paper. However, the algebra associated with the various derivations becomes significantly more complicated. This is the reason for
} 
The terminal value of the renewable resource stock depends in part on the tariff used by the buyer.

One can think of these alternate terminal stock levels as the outcomes of different games. One way of comparing these outcomes is to compare the resultant stock levels. In this connection, we say that game 1 is more resource conserving than game 2 if and only if $x_{1}{ }^{T}>x_{2}{ }^{T}$, where $x_{i}{ }^{T}, i=1,2$ is the terminal value of the resource stock in game $i=1,2$. We determine the different harvest trajectories by deriving a differential equation satisfied by the equilibrium $h(t)$. When we are able to compare the various differential equations without resorting to additional assumptions, we shall do so. However, the reader should note that because of the complexity of the underlying mathematics, in some cases it will not be possible to obtain general results.

Let us now consider the benchmark case in which there is free trade. In this case, the buyer is passive, he sets $n(t)=0$ or $v(t)=1$, and the seller solves a standard control problem. When the harvest cost function is stock independent, the optimal competitive harvest rate solves

$$
\left\{p^{\prime}(h)-c^{\prime \prime}(h)\right\} \ddot{\mathscr{V}}-(r-b)\left\{p(h)-c^{\prime}(h)\right\}=0,
$$

and when the harvest cost function is stock dependent, the optimal competitive harvest rate solves

$$
p^{\prime}(h) \ddot{\ddot{y}}-(r-b)\{p(h)-c(x)\}-b x c^{\prime}(x)=0
$$

In what follows, we compare the differential equation satisfied by the optimal harvest level in section 3 with equation (6) and that in section 4 with equation (7).

\section{The Stock Independent Harvest Cost Function and Open Loop Tariffs}

We now derive the optimal open loop unit and ad valorem tariffs for our single buyer

sticking with the linear natural growth function. 
(monoposonist). The reader should note that although open loop tariffs are generally dynamically inconsistent (Karp and Newbery (1993)), for the case studied in this section, these open loop tariffs are dynamically consistent. Before we explain why this is the case, let us first understand what would happen were these tariffs to be dynamically inconsistent. If these tariffs were dynamically inconsistent, then at some time $t>0$ the buyer would want—if he could—-to deviate from the tariff trajectory he announced at the beginning of the game (at time $t=0$ ) and announce a different tariff trajectory. The competitive seller in this paper is forward looking. As such, she would anticipate the buyer's desire to change the tariff trajectory he announced at the beginning of the game and hence this tariff would fail to achieve its intended objectives. In the class of Stackelberg games analyzed in this paper, the stock independence of the harvest cost function accounts for the dynamic consistency of the optimal solution. To see this clearly, we now derive, in turn, the open loop unit and the ad valorem tariffs.

\subsection{The Open Loop Unit Tariff}

We solve the buyer's problem using a method used previously by Simaan and Cruz (1973), Karp (1984), and Batabyal (1996). The basic idea is as follows: The buyer treat's the seller's first order condition as an ordinary constraint and her costate variable as a state variable. These two conditions and suitable boundary conditions convert the differential game into a control problem for the buyer.

When the seller takes the buyer's unit tariff $n(t)$ as given, the first order necessary conditions to her problem are

$$
p(h)-n-c^{\prime}(h)-\ddot{\mathrm{e}}=0
$$

and

$$
\ddot{\mathrm{e}}=(r-b) \ddot{\mathrm{e}},
$$


where $\ddot{e}(t)$ is the costate variable. ${ }^{8}$ This costate variable gives us the seller's marginal utility of one more unit of the resource stock at time $t$. Now solving for $n$ from equation (8) and substituting in equation (1), we get

$$
J_{b}=\int_{0}^{T} e^{-r t}\left[u(h)-\left\{c^{\prime}(h)+\ddot{\mathrm{e}}\right\} h\right] d t .
$$

Equation (10) gives the buyer's payoff as the present discounted stream of the difference between the utility of consuming $h(t)$ and the sum of the marginal harvest cost times the harvest $h(t)$ and the term $\ddot{h}$. This last term is the total instantaneous rent paid by the buyer for the resource $x$.

In order to keep the buyer's problem a one state variable problem, let us eliminate ë from (10) by using (9). Solving equation (9), it is clear that $\ddot{e}(t)=0$. Substituting this value of $\ddot{e}$ into (10) we get

$$
J_{b}=\int_{0}^{T} e^{-r t}\left[u(h)-c^{\prime}(h) h\right] d t .
$$

Note that we have now converted the buyer's problem from one of maximizing (1) over $n$ subject to (5) to one of maximizing (11) over $h$ subject to (5). The first order necessary conditions to this problem are

$$
p(h)-c^{\prime}(h)-h c^{\prime \prime}(h)-o ́=0,
$$

and

\section{8}

Equation (9) describes a jump state constraint. In other words, the initial value of ë, ë(0), is free and the value of this jump state variable at any arbitrary point in time is determined by current and/or future events. Put differently, equation (9) is not a fixed initial state constraint for the buyer. For more on jump state constraints see Karp and Newbery (1993). 


$$
\ddot{\mathbf{g}}=(r-b) \text { ó, }
$$

where ó $(t)$ is the costate variable. Inspecting (12), we see that the solution to the buyer's problem does not depend on the initial stock of the resource $x_{0}$. This explains why the optimal solution to the buyer's problem is dynamically consistent. Put differently, because it is optimal to set $\ddot{e}(t)=0$, the total instantaneous rent paid by the buyer for the resource $x$ does not affect his maximization problem. Therefore, the question of altering the total instantaneous rent paid to the seller over time does not arise.

To find the differential equation satisfied by the optimal $h(t)$ when our buyer uses a unit tariff, differentiate (12) with respect to time and then use (13) to simplify the resulting expression. This yields

$$
\left\{p^{\prime}(h)-2 c^{\prime \prime}(h)-h c^{\prime \prime \prime}(h)\right\} \ddot{\nabla}-(r-b)\left\{p(h)-c^{\prime}(h)-h c^{\prime \prime}(h)\right\}=0,
$$

where $p\{h(T)\}=c^{\prime}\{h(T)\}+h(T) c^{\prime \prime}\{h(T)\}$ is the boundary condition for $h$. Comparing equations (14) and

(6) it is clear that the optimal harvest level when the buyer uses a unit tariff is not the same as the optimal harvest level when this buyer is passive. When the harvest cost function is quadratic, i.e., when $c(h)=h^{2} / 2$, the differential equation for the optimal harvest with a unit tariff approximates the differential equation for the optimal harvest when the buyer is passive. This notwithstanding, there are no straightforward necessary or sufficient conditions under which(6) and(14) coincide. The differential equation for the optimal unit tariff is found by differentiating (8) and then using (9) to simplify the ensuing expression. This gives

$$
\ddot{n}-(r-b) n=\left\{p^{\prime}(h)-c^{\prime}(h)\right\} \ddot{y}-(r-b)\left\{p(h)-c^{\prime}(h)\right\},
$$

where $\ddot{b}$ is given by (14) and $n(T)=p\{h(T)\}-c^{\prime}\{h(T)\}$ is the boundary condition.

\subsection{The Open Loop Ad Valorem Tariff}

We now derive the solution for the open loop ad valorem tariff when the buyer's objective is given by (2). To maximize (4) subject to (5), we first form the seller's current value Hamiltonian. The pertinent 
first order necessary conditions are

$$
v p(h)-c^{\prime}(h)-\ddot{\mathrm{e}}=0,
$$

and (9). Now solve for $v$ from (16), substitute into (2), and then simplify the resulting expression. We get

$$
J_{b}=\int_{0}^{T} e^{-r t}\left[u(h)-\left\{c^{\prime}(h)+\ddot{\mathrm{e}}\right\} h\right] d t .
$$

Comparing equations (17) and (10) it is clear that these two objective functionals are identical. This tells us that the renewable resource buyer's payoff is policy invariant. Further, note that because $\ddot{e}(t)=0$, the constraint in both cases is (5). From this we conclude that the open loop unit and ad valorem tariffs are equivalent. Consequently, they will both give rise to the same time profile of harvests and hence to the same terminal level of the resource stock. We now discuss the implications of these findings.

\subsection{Discussion}

From the previous paragraph we conclude that the unit payment from the buyer to the seller is $p(h)-n(t)$ in the case of the unit tariff and $v(t) p(h)$ in the case of the ad valorem tariff. Moreover because $\ddot{\mathrm{e}}(t)=0$, it is easy to verify that $p(h)-n(t)=v(t) p(h)=c^{\prime}(h)$. Put differently, when a single buyer trades with competitive sellers, this buyer gains nothing by using both tariffs simultaneously. Indeed, one tariff is superfluous and it is optimal to set this tariff equal to zero.

Equation (13) tells us that ó $(t)=0, \forall t$. In other words, the buyer's marginal utility of one additional unit of the resource stock is zero. Using this in (12) we get an equation for the domestic price of the renewable resource in the importing nation. That equation is

$$
p(h)=c^{\prime}(h)+h(t) c^{\prime \prime}(h), \forall t .
$$


The reader will note that the domestic price of the renewable resource in the importing nation does not depend on the initial value of the resource stock $x_{0}$.

Since the optimal unit and ad valorem tariffs are equivalent, a comparative exercise involving these two trade policy instruments is not relevant. Recall that the objective of the importing nation is to encourage the conservation of the renewable resource. In this regard we note that because the tariffs studied here are dynamically consistent, they will achieve theirintended conservation objectives, albeitindirectly. Having said this, we should also point out that if an importing nation's objective is to encourage conservation of the renewable resource in the exporting countries, then tariffs are not the ideal policy instruments. Why not? This is because tariffs target trade and the direct effect of the tariff is to discourage domestic consumption in the importing nation. Tariffs do not do anything directly to encourage conservation of the renewable resource in the exporting nations. Consequently, from the standpoint of resource conservation, tariffs are blunt policy instruments. We now analyze the Stackelberg differential game between our single buyer and competitive sellers when the harvest cost function is stock dependent.

\section{The Stock Dependent Harvest Cost Function and Open Loop Tariffs}

When the harvest cost function is stock dependent, the optimal open loop unit and ad valorem tariffs are dynamically inconsistent. As indicated in section 3, this means that at some time $t>0$ the buyer will want - if he can — to deviate from the tariff trajectory he announced at time $t=0$ and announce a different tariff trajectory. The competitive seller in this paper is forward looking. Therefore, she will foresee the buyer's desire to alter the tariff trajectory he announced at the beginning of the game and hence this tariff will fail to attain its intended conservation goals. To comprehend this crucial feature of the optimal policies clearly, we now derive the optimal open loop unit and ad valorem tariffs. 


\subsection{The Open Loop Unit Tariff}

Recall from section 2 that the stock dependent harvest cost function is $c(x) h$. We follow the section 3 method to solve our buyer's problem. Suppose the seller takes the buyer's unit tariff $n(t)$ as given. Then the first order necessary conditions to her problem are

$$
p(h)-n-c(x)-\ddot{\mathrm{e}}=0
$$

and

$$
\ddot{\ddot{e}}=(r-b) \ddot{\mathrm{e}}+c^{\prime}(x) h,
$$

where $\ddot{e}(t)$ is the costate variable. This costate variable gives us the seller's marginal utility of one more unit of the resource stock at time $t$. Comparing (20) with (9) it is immediately clear that when the harvest cost function is stock dependent, $\ddot{e}(t) \neq 0$. In words, the rent on the marginal unit of the resource stock is typically not equal to zero. Now solving for $n$ from equation (19) and then substituting into equation (1), we get

$$
J_{b}=\int_{0}^{T} e^{-r t}[u(h)-\{c(x)+\ddot{\mathrm{e}}\} h] d t .
$$

Equation (21) gives the buyer's payoff as the present discounted stream of the difference between the utility of consuming $h(t)$ and the sum of the cost of harvesting $h(t)$ and the term ë $h$. As in section 3, this last term can be interpreted as the total instantaneous rent paid by the buyer for the resource $x$.

In order to keep the buyer's problem a single state variable problem, we now eliminate ë from (21) by using (20). Integrating equation (20) we get 


$$
\ddot{\mathrm{e}}(t)=e^{(b-r)(T-t)} \ddot{\mathrm{e}}(T)-e^{-(b-r) t} \int_{t}^{T} e^{(b-r) m} c^{\prime}(x) h d m .
$$

Substituting this value of $\ddot{\mathrm{e}}(t)$ from (22) into (21) we obtain

$$
J_{b}=\int_{0}^{T} e^{-r t}\left[u(h)-c(x) h-\left\{e^{(b-r)(T-t)} \ddot{\mathrm{e}}(T)-e^{-(b-r) t} \int_{t}^{T} e^{(b-r) m} c^{\prime}(x) h d m\right\} h\right] d t .
$$

Equation (23) tells us that for any time path of $h(t)$, the buyer's objective functional is maximized by setting ë $(T)=0$.

So, the buyer drives the seller's rent to zero at the end of the game. Now substitute $\ddot{e}(T)=0$ into (23) and reverse the order of integration of the last term in (23). This gives

$$
J_{b}=\int_{0}^{T} e^{-r t}\left[u(h)-c(x) h+c^{\prime}(x) h\left\{e^{b t} x_{0}-x\right\}\right] d t .
$$

As desired, we now have a single state variable problem for our buyer. Specifically, we have converted the buyer's problem from one of maximizing (1) over $n$ subject to (5) to one of maximizing (24) over $h$ subject to (5). Comparing equations (24) and (11) we see that unlike the case analyzed in section 3, when the harvest cost function is stock dependent, the initial value of the resource stock $x_{0}$ enters the buyer's objective functional. The first order necessary conditions to our buyer's problem are

$$
p(h)-c(x)+c^{\prime}(x)\left\{e^{b t} x_{0}-x(t)\right\}-\mathbf{o}=0,
$$

and

$$
\ddot{9}=(r-b) \text { ó }+2 c^{\prime}(x) h-c^{\prime \prime}(x) h\left\{e^{b t} x_{0}-x(t)\right\},
$$


where ó $(t)$ is the costate variable. Equation (25) tells us that when the harvest cost function is stock dependent, the solution to the buyer's problem does depend on the initial stock of the renewable resource $x_{0}$. What this means is that if the buyer were able to revise — at some time $m>0$ — the tariff he initially announced at the beginning of the game, then $x_{0}$ in (25) would have to be replaced with $x(m)$ and the solution for all $t>m$ would be different. In other words, the buyer's optimal solution is dynamically inconsistent. From (25) and (26) it is clear that the optimal solution is dynamically consistent if and only if the harvest cost function is unrelated to the stock of the resource. Indeed, this is what we demonstrated in our analysis of the stock independent harvest cost function in section 3.

Before deriving a differential equation satisfied by the optimal $h(t)$, a comment on the salience of constraint (20) is in order. The seller of the renewable resource in this paper has no market power and she solves a dynamic but standard control problem. In contrast, the buyer exerts market power and he is constrained by the dynamic maximizing behavior of the seller. These two features of the buyer's problem together tell us that his control problem is non-standard. Put differently, because the seller's problem is dynamic and the buyer exerts market power, a "rational expectations" constraint—given by equation (20) — is introduced into the buyer's problem. ${ }^{9}$ The presence of this constraint makes our buyer's problem a non-standard control problem.

To find the differential equation satisfied by the optimal $h(t)$ when our buyer uses a unit tariff, we differentiate (25) with respect to time and then use (26) to simplify the resulting expression. This process gives

9

In footnote 8, we called this "rational expectations" constraint a jump state constraint. For more on these matters, see Karp (1984) and Karp and Newbery (1993). 


$$
\begin{gathered}
p^{\prime}(h) \ddot{\partial}-(r-b)\left\{p(h)-c(x)+e^{b t} x_{0} c^{\prime}(x)-c^{\prime}(x) x\right\}+b c^{\prime}(x)\left\{e^{b t} x_{0}-2 x\right\}+ \\
c^{\prime \prime}(x)\left\{b x_{0} x-h x_{0}-b x^{2}+e^{b t} h x_{0}\right\}=0
\end{gathered}
$$

where $p\{h(T)\}=c\{x(T)\}-c^{\prime}\{x(T)\}\left\{e^{b T} x_{0}-x(T)\right\}+o(T)$ is the boundary condition for $h$. Inspecting (27), it is clear that the exogenously given initial condition $x(0)=x_{0}$ affects the temporal behavior of the optimal harvest $h(t)$. Comparing equations (27) and (7) we see that as in section 3, the optimal harvest level when our buyer uses a unit tariff and the harvest cost function is stock dependent is not the same as the optimal harvest level when this buyer is passive. Moreover, there are no obvious necessary or sufficient conditions under which equations (7) and (27) coincide. The differential equation for the optimal unit tariff is found by differentiating (19) with respect to time and then using (20) to simplify the resulting expression. This gives

$$
\begin{gathered}
\ddot{n y}-(r-b) n=(r-b)\left\{e^{b t} x_{0} c^{\prime}(x)-c^{\prime}(x) x\right\}-b c^{\prime}(x)\left\{e^{b t} x_{0}-x\right\}- \\
c^{\prime \prime}(x)\left\{b x_{0} x-h x_{0}-b x^{2}+e^{b t} h x_{0}\right\},
\end{gathered}
$$

where $\ddot{\vec{y}}$ is given by (27) and the boundary condition is $n(T)=p\{h(T)\}-c\{x(T)\}$.

\subsection{The Open Loop Ad Valorem Tariff}

Even when the harvest cost function is stock dependent, the optimal open loop unit and $a d$ valorem tariffs are equivalent. We now demonstrate this fact. When the seller takes the buyer's ad valorem tariff as given, the first order necessary conditions to her control problem are

$$
v p(h)-c(x)-\ddot{\mathrm{e}}=0,
$$

and (20). Solving for $v$ from (29), substituting into (2), and then simplifying, we get

$$
J_{b}=\int_{0}^{T} e^{-r t}[u(h)-\{c(x)+\ddot{\mathrm{e}}\} h] d t .
$$


Comparing (30) and (21) it is clear that these two objective functionals are identical. Further, before the rent $\ddot{\mathrm{e}}(t)$ has been eliminated from the objective functionals (21) and (30), the constraints for both the problems are given by (5) and (20). This tells us that the optimal unit and the ad valorem tariffs are equivalent. In particular, both tariffs are plagued by the problem of dynamic inconsistency and it does not matter which tariff the buyer uses because his payoff with either tariff is the same. From (19) and (29), the reader can easily verify that $p(h)-n(t)=v(t) p(h)=c(x)+\ddot{e}$. Hence, one tariff is redundant and our buyer gains nothing by using both tariffs in unison. We now discuss the nexuses between the form of the harvest cost function, the buyer's trade (tariff) policies, and the efficacy of these policies in promoting the conservation of the renewable resource under study.

\subsection{Discussion}

Upon rearranging terms in equation (25), we get an equation for the domestic price of the renewable resource in the importing nation. That equation is

$$
p(h)=c(x)-c^{\prime}(x)\left\{e^{b t} x_{0}-x(t)\right\}+o ́(t), \forall t
$$

where ó $(t)$ is the buyer's marginal utility of an additional unit of the resource at time $t$. Note that because the harvest cost function is stock dependent, unlike the case examined in section 3.3 (see equation (18)), the buyer's marginal utility of one more unit of the resource stock ó $(t)$ is now nolonger equal to zero. Also, the initial value of the resource stock now affects the domestic price of the renewable resource in the importing nation. Comparing equations (18) and (31) we see that, in general, it is not possible to determine whether the domestic price is higher with the stock independent or with the stock dependent harvest cost function. Further, note that $x_{0}$ affects the optimal solution when the harvest cost function is stock dependent. In contrast, $x_{0}$ does not affect the optimal solution in the case of the stock independent harvest 
cost function. Consequently, in general, it is not possible to determine whether the terminal value of the resource stock $x(T)$ is higher with the stock independent or with the stock dependent harvest cost function.

The analysis in this paper has shown that attempts to promote renewable resource conservation by means of trade policies are problematic in more ways than one. Let us now discuss this salient point in greater detail. The analysis in Karp and Newbery (1993) and in Batabyal (1998) tells us that given a choice between dynamically inconsistent and consistent policies, an economic agent will typically choose dynamically inconsistent policies because inconsistent policies result in a higher payoff. In the context of this paper, this tells us than even when the open loop unit and ad valorem tariffs are dynamically inconsistent — and this happens when the harvest cost function is stock dependent— the buyer in the importing nation will prefer to use these inconsistent trade policies rather than follow a dynamically consistent course of action. However, inconsistent policies are not credible and hence the tariff trajectory announced by the buyer at the beginning of the game will not be believed by the sellers and therefore inconsistent policies will fail to achieve their resource conservation objectives.

In contrast, when the harvest cost function is stock independent, the optimal open loop tariffs are dynamically consistent and hence believable by the sellers of the resource. Consequently, in this case, the buyer's trade policies (tariffs) will, albeit indirectly, attain their resource conservation objectives. As indicated previously in section 3.3, in an ideal situation, trade policies such as tariffs should not be used to promote the conservation of renewable resources. This is because tariffs reduce the domestic consumption of the traded resource in the importing nation and hence get at the conservation issue only indirectly. However, if sellers are unwilling and/or unable to take measures in their own countries to promote resource conservation, possibly because of the lack of apposite property rights, then tariffs are one imperfect 
instrument with which sellers can be encouraged to undertake the appropriate conservation measures.

Although tariffs are an imperfect way of promoting conservation, the analysis in this paper has shown that they may not work as desired. This is because the credibility of the optimal tariffs depends on the form of the harvest cost function and this form is not controllable by the buyer. This crucial point has not been recognized previously in the literature on international trade in renewable resources. We have already noted that the stock dependent cost function is the more appropriate cost function for endangered renewable resources such as the African elephant. Resources like the African elephant are endangered at least in part because adequate domestic measures have not been taken in the pertinent countries to prevent overexploitation. In the case of the African elephant, the relevant countries include South Africa, Uganda, Zambia, and Zimbabwe. It is for these endangered resources-where the appropriate domestic conservation measures have not been taken - that imperfect supra-national measures such as trade policies are most needed. Unfortunately, the analysis in this paper tells us that trade policies are likely to be ineffective (because they are not credible) precisely when they are most needed (when the harvest cost function is stock dependent).

\section{Conclusions}

This paper studied a Stackelberg differential game model of international trade in renewable resources. We analyzed trade in a renewable resource between a single buyer who leads and competitive sellers who follow. The government in the importing nation uses trade policies (unit and ad valorem tariffs) to indirectly promote the conservation of the renewable resource being studied. The optimal open loop unit and ad valorem tariffs are equivalent and hence the buyer gains nothing by using both tariffs simultaneously. The efficacy of trade policies in promoting resource conservation depends fundamentally on the form of 
the harvest cost function. The analysis conducted here shows that because of credibility problems, trade policies such as tariffs are likely to be ineffective in promoting the conservation of threatened renewable resources.

The analysis in this paper can be extended in a number of different directions. In what follows, we suggest two possible extensions. First, it would be useful to determine the properties of the optimal open loop tariffs when in addition to the buyer, the seller also obtains utility from consuming the renewable resource. Second, it would be interesting to study the trade game between our monopsonistic buyer and a monopolistic seller of the renewable resource. In this case the buyer and the seller would have market power. Consequently, if the buyer leads, then it would be interesting to know, inter alia, whether he is able to use trade policies to reduce or neutralize the seller's market power. An examination of these aspects of the problem will allow richer analyses of the connections between trade, trade policies, and the conservation of renewable resources. 


\section{References}

Barbier, Edward, Burgess, Joanne, Swanson, Timothy, and Pearce, David. 1990. Elephants, Economics, and Ivory. Earthscan, London, United Kingdom.

Barbier, Edward, and Schulz, Carl-Erik. 1997. Wildlife, Biodiversity, and Trade, Environment and Development Economics, 2, 145-172.

Batabyal, Amitrajeet. 1996. Consistency and Optimality in a Dynamic Game of Pollution Control I: Competition, Environmental and Resource Economics, 8, 205-220.

Batabyal, Amitrajeet. 1998. Environmental Policy in Developing Countries: A Dynamic Analysis, Review of Development Economics, 2, 293-304.

Brander, James, and Taylor, Scott. 1998. Open Access Renewable Resources: Trade and Trade Policy in a Two-Country Model, Journal of International Economics, 44, 181-209.

Bulte, Erwin, and van Kooten, Cornelis. 1999. Economic Efficiency, Resource Conservation, and the Ivory Trade Ban, Ecological Economics, 28, 171-181.

Clark, Colin. 1973. The Economics of Overexploitation, Science, 181, 630-634.

Emami, Ali, and Johnston, Richard. 2000. Unilateral Resource Management in a Two-Country General Equilibrium Model of Trade in a Renewable Fishery Resource, American Journal of Agricultural Economics, 82, 161-172.

Heltberg, Rasmus. 2001. Impact of the Ivory Trade Ban on Poaching Incentives: A Numerical Example, Ecological Economics, 36, 189-195.

Jablonski, David. 1991. Extinctions: A Paleontological Perspective, Science, 253, 754-757. 
Karp, Larry. 1984. Optimality and Consistency in a Differential Game With Non-Renewable Resources, Journal of Economic Dynamics and Control, 8, 73-97.

Karp, Larry., and Newbery, David. 1993. Intertemporal Consistency Issues in Depletable Resources, in Allen Kneese and James Sweeny, (Eds.), Handbook of Natural Resource and Energy Economics, Volume 3. Elsevier, Amsterdam, The Netherlands.

Maestad, Ottar. 2001. Timber Trade Restrictions and Tropical Deforestation: A Forest Mining Approach, Resource and Energy Economics, 23, 111-132.

Meredith, Martin. 2001. Africa's Elephant. Hodder and Stoughton, London, United Kingdom.

Pimm, Stuart, Russell, Gareth, and Gittleman, John. 1995. The Future of Biodiversity, Science, 269, 347350.

Schulz, Carl-Erik. 1997. Trade Sanctions and Effects on Long-Run Stocks of Marine Mammals, Marine Resource Economics, 12, 159-178.

Simaan, Marwan, and Cruz, Jose. 1973. Additional Aspects of the Stackelberg Strategy in Non-Zero Sum Games, Journal of Optimization Theory and Applications, 11, 613-626. 